\title{
HUBUNGAN ANTARA PENGETAHUAN DAN PENDIDIKAN IBU DENGAN PEMBERIAN MP-ASI PADA BAYI <6 BULAN DI RB CITRA PALEMBANG TAHUN 2017
}

\author{
Era Mardia Sari ${ }^{1}$, Nisa Afra Meidina ${ }^{2}$ \\ Dosen Tetap STIK Siti Khadijah Palembang \\ Email : Eramardiasari@gmail.com
}

\begin{abstract}
ABSTRAK
MP-ASI adalah makanan yang diberikan selain ASI ketika bayi telah berusia 6 bulan. MPASI wajib diberikan kepada bayi saat usia telah mencapai 6 bulan karena pada usia tersebut ASI sudah tidak dapat memenuhi kebutuhan si bayi. Tujuan penelitian untuk mengetahui hubungan antara pengetahuan dan pendidikan ibu dengan pemberian MP-ASI pada bayi usia $<6$ bulan di RB Citra Palembang Tahun 2017. Penelitian ini menggunakan metode Survey Analitik dengan pendekatan Cross Sectional. Penelitian dilakukan pada tanggal 30 Juni 2017. Populasi pada penelitian adalah seluruh ibu yang memiliki bayi usia $<6$ bulan di RB Citra Palembang pada bulan Maret - Mei yaitu sebanyak 206 orang, dan sampel sebanyak 43 orang. Pengambilan sampel mengunakan metode Non Random Sampling dengan teknik Accidental Sampling. Berdasarkan uji statistik pengetahuan diperoleh nilai $p$ value $0,001<0,05$, sedangkan pendidikan diperoleh $p$ value $0,017<0,05$, ini menunjukkan adanya hubungan bermakna antara pengetahuan dan pendidikan ibu terhadap pemberian MPASI pada bayi usia <6 bulan di RB Citra Palembang Tahun 2017. Diharapkan bagi petugas kesehatan untuk memberikan penyuluhan kesehatan untuk memberikan informasi kesehatan sehingga dapat meningkatkan pengetahuan dan pemahaman ibu khususnya tentang pemberian MP-ASI yang tepat.
\end{abstract}

Kata kunci : pengetahuan, pendidikan, MP-ASI

\begin{abstract}
Complementary foods is other foods besides breast milk for infants from six month onwards. Complementary food must be given to infants at 6 month of age, because at that age breast milk is no longer enough to meet the nutritional needs of the infants. The aim of this study is to know about the correlation between mother's knowledge and education with complementary feeding of infants under 6 month of age in Citra Maternity Clinic Palembang in 2017. This research used Analytical Survey method with Cross Sectional approach. This research has been done in June $30^{\text {th }}, 2017$. The population of this research is all of mothers who have infants under 6 month of

age in Citra Maternity Clinic on March - Mei 2017 was 206 respondents. The sample of this study was 43 respondents, used by non random sampling. The technique of this study was accidental sampling. Based on statistic test of knowledge, got the $\mathrm{p}$ value $0.001<0.05$, and education got $\mathrm{p}$ value $0.017<0.05$. Based on the result of this research, there is significant correlation between mother's knowledge and education with complementary feeding of infants under 6 month of age in Citra Maternity Clinic Palembang in 2017. It hoped that the health workers can give information about complementary feeding to increase the knowledge about complementary feeding properly.
\end{abstract}

Keywords : knowledge, education, complementary feeding 



\section{PENDAHULUAN}

Pemberian ASI eksklusif pada bayi hingga usia 6 bulan merupakan hak bagi semua bayi. Berbagai penelitian yang telah dilakukan semuanya menunjukkan bahwa ASI memiliki peran yang sangat besar dalam membantu pertumbuhan dan perkembangan bayi secara optimal (Citerawati, 2016).

Saat bayi menginjak usia 7 bulan, ASI tetap menjadi sumber zat gizi utama bagi bayi karena mudah dicerna. Namun, ASI tidak lagi dapat mencukupi kebutuhan gizi bayi karena kebutuhan gizi bayi yang semakin meningkat. Sehingga, bayi memerlukan makanan tambahan yang mendampingi ASI sebagai makanan utamanya yang disebut dengan makanan pendamping ASI (MP-ASI) (Fikawati, 2015).

Ada beberapa faktor yang mempengaruhi ibu memberikan makanan tambahan pada bayi antara lain faktor kesehatan bayi, faktor kesehatan ibu, faktor pengetahuan, faktor pendidikan, faktor pekerjaan, faktor petugas kesehatan, faktor budaya dan faktor ekonomi (Kusmiyati, 2014).
Berdasarkan data yang diperoleh dari studi pendahuluan yang dilakukan di RB Citra Palembang pada saat Posyandu, dari 28 ibu yang memiliki bayi usia 0-6 bulan, ada sebanyak 9 ibu yang memberikan MP-ASI pada bayi usia 0-6 bulan baik berupa cair maupun padat sedangkan 
19 ibu lainnya memberikan ASI Eksklusif pada bayinya.

Tujuan dari penelitian untuk mengetahui adanya "Hubungan Antara Pengetahuan dan Pendidikan Ibu dengan Pemberian MP-ASI pada Bayi <6 Bulan di RB Citra Palembang Tahun 2017”.

\section{METODELOGI PENELITIAN}

Jenis penelitian ini bersifat analitik, metode yang dipakai menggunakan pendekatan Cross Sectional, dimana pengumpulan data baik variabel independen (pengetahuan dan pendidikan) maupun variabel dependen (pemberian MP-ASI <6 bulan) dilakukan dalam waktu bersamaan. Penelitian telah dilaksanakan di RB Citra Palembang. Penelitian dilaksanakan pada tanggal 30 Juni 2017. Populasi pada penelitian ini adalah seluruh ibu yang memiliki bayi usia < 6 bulan di RB Citra Palembang pada bulan Maret - Mei yaitu sebanyak 206 orang. Sampel pada penelitian ini adalah ibu yang datang ke posyandu yang memiliki bayi usia $<6$ bulan di RB Citra Palembang sebanyak 43 responden

\section{HASIL PENELITIAN DAN PEMBAHASAN}

Responden pada penelitian ini adalah seluruh ibu yang memiliki bayi usia $<6$ bulan pada saat posyandu di RB Citra Palembang. Adapun distribusi frekuensi dan persentase dari variabel dependen (pemberian MP-ASI) dan variabel independen (pengetahuan dan pendidikan) dan dapat dilihat pada tabel berikut :

Tabel 1

Distribusi Frekuensi Responden Berdasarkan Pemberian MP-ASI Pada Bayi Usia <6 Bulan Di RB Citra

Palembang Tahun 2017

\begin{tabular}{llll}
\hline No. & $\begin{array}{c}\text { Pemberian } \\
\text { MP-ASI }\end{array}$ & $\mathbf{N}$ & $\%$ \\
\hline 1. & Ya & 10 & 23,3 \\
2. & Tidak & 33 & 76,7 \\
\hline & Total & $\mathbf{4 3}$ & $\mathbf{1 0 0}$ \\
\hline
\end{tabular}

Berdasarkan tabel 1 dapat diketahui bahwa dari 43 responden, yang memberikan MP-ASI sebanyak 10 responden (23,3\%) lebih sedikit dibandingkan responden yang tidak memberikan MP-ASI sebanyak 33 responden $(76,7 \%)$.

Tabel 2

Distribusi Frekuensi Responden Berdasarkan Pengetahuan Di RB Citra Palembang Tahun 2017

\begin{tabular}{llll} 
No. & Pengetahwan & $\mathbf{N}$ & $\%$ \\
1. & Baik & 19 & 44,2 \\
2. & Kurang Baik & 24 & 55,8 \\
& Total & $\mathbf{4 3}$ & $\mathbf{1 0 0}$ \\
\hline & Berdasarkan tabel & 2 & dapat diketahui
\end{tabular}

bahwa dari 43 responden yang memiliki 
pengetahuan baik sebanyak 19 reponden (44,2\%) lebih sedikit dibandingkan responden yang memiliki pengetahuan kurang baik sebanyak 24 responden $(55,8 \%)$.

Tabel 3

Distribusi Frekuensi Responden Berdasarkan Pendidikan Di RB Citra Palembang Tahun 2017

\begin{tabular}{llll}
\hline No. & Pendidikan & N & \% \\
\hline 1. & Rendah & 12 & 27,9 \\
2. & Tinggi & 31 & 72,1 \\
\hline & Total & $\mathbf{4 3}$ & $\mathbf{1 0 0}$
\end{tabular}

Berdasarkan tabel 3 dapat diketahui bahwa dari 43 responden dengan pendidikan rendah sebanyak 12 reponden $(27,9 \%)$ lebih sedikit dibandingkan responden yang memiliki pendidikan tinggi yaitu sebanyak 31 responden $(72,1 \%)$.

Adapun penelitian dilakukan untuk mengetahui hubungan antara variabel independen (pengetahuan dan pendidikan) dengan variabel dependen (pemberian MP-ASI) dapat dilihat pada tabel berikut:

\section{Tabel 4}

\section{Distribusi Responden Pemberian MP-ASI}

\section{Berdasarkan Variabel Pengetahuan di Rumah Bersalin Citra Palembang Tahun 2017}

\begin{tabular}{|c|c|c|c|c|c|}
\hline \multirow{3}{*}{$\begin{array}{l}\text { Pengetahua } \\
\text { n }\end{array}$} & \multicolumn{4}{|c|}{ Pemberian MP-ASI } & \multirow{3}{*}{$p$ value } \\
\hline & \multicolumn{2}{|c|}{ Ya } & \multicolumn{2}{|c|}{ Tidak } & \\
\hline & $\mathbf{n}$ & $\%$ & $\mathbf{n}$ & $\%$ & \\
\hline Baik & 0 & 0,0 & 19 & 100,0 & \\
\hline Kurang Baik & 10 & 41,7 & 14 & 58,3 & 0,001 \\
\hline Jumlah & 10 & 23,3 & 33 & 76,7 & \\
\hline
\end{tabular}

bahwa dari 19 responden dengan pengetahuan baik yang memberikan MP-ASI sebanyak 0 responden $(0,00 \%)$ dan yang tidak memberikan MP-ASI sebanyak 19 responden (100,0\%), sedangkan dari 24 responden yang pengetahuan kurang baik yang memberikan MP-ASI sebanyak 10 responden $(41,7 \%)$ dan yang tidak memberikan MP-ASI sebanyak 14 responden $(58,3 \%)$.

Bila dilihat dari hasil uji statistik dengan menggunakan Chi-Square menunjukkan nilai $p$ value $(0,001)$ lebih kecil dari $\alpha(0,05)$ artinya ada hubungan bermakna antara pengetahuan ibu dengan Pemberian MP-ASI pada Bayi Usia <6 Bulan.

Berdasarkan hasil penelitian, teori dam penelitian terkait peneliti berasumsi bahwa pengetahuan dapat mempengaruhi pola pikir seseorang. Dalam hal pemberian MP-ASI pada bayi usia $<6$ bulan. Semakin baik pengetahuan responden maka cenderung untuk tidak memberikan MP-ASI, sebaliknya jika pengetahuan responden kurang baik maka responden lebih cenderung memberikan MP-ASI 
pada bayinya karena ketidaktahuan atau kurangnya wawasan responden mengenai pemberian MP-ASI pada bayi usia < 6 bulan yang memberikan dampak buruk bagi bayi seperti gangguan pencernaan.

Tabel 5

Distribusi Responden Pemberian MP-ASI

Berdasarkan Variabel Pendidikan di Rumah Bersalin Citra Palembang

Tahun 2017

\begin{tabular}{|c|c|c|c|c|c|}
\hline \multirow{3}{*}{ Pendidikan } & \multicolumn{4}{|c|}{ Pemberian MP-ASI } & \multirow[b]{2}{*}{$p$ Value } \\
\hline & \multicolumn{2}{|c|}{$\mathbf{Y a}$} & \multirow[b]{2}{*}{$\mathbf{n}$} & \multirow[b]{2}{*}{$\%$} & \\
\hline & $\mathbf{n}$ & $\%$ & & & \\
\hline Rendah & 6 & 50,0 & 6 & 50,0 & \\
\hline Tinggi & 4 & 12,9 & 27 & 87,1 & 0,017 \\
\hline Jumlah & 10 & 23,3 & 33 & 76,7 & \\
\hline
\end{tabular}

Berdasarkan tabel 5.5 diatas diketahui

bahwa dari 12 responden menunjukan bahwa proporsi responden dengan pendidikan rendah yang memberikan MP-ASI sebanyak 6 responden $(50,0 \%)$ dan yang tidak memberikan MP-ASI sebanyak 6 responden $(50,0 \%)$, sedangkan dari 31 responden dengan pendidikan tinggi yang memberikan MP-ASI sebanyak 4 responden $(12,9 \%)$ dan yang tidak memberikan MP-ASI sebanyak 27 responden $(87,1)$.

Bila dilihat dari hasil uji statistik dengan menggunakan Chi-Square menunjukan nilai $p$ value $(0,017)$ lebih kecil dari $\alpha(0,05)$ artinya ada hubungan bermakna antara pendidikan ibu dengan Pemberian MP-ASI pada Bayi Usia $<6$ Bulan.

Berdasarkan hasil penelitian serta teori bahwa ada hubungan yang bermakna antara pendidikan dengan pemberian MP-ASI pada bayi usia $<6$ bulan. Hal ini dikarenakan dengan pendidikan yang tinggi kemungkinan seseorang akan lebih tahu dan mudah menerima informasi yang telah didapat dari pendidikannya, sehingga tidak tertinggal oleh adanya informasi yang baru yang dapat mengubah perilaku seseorang. termasuk juga tidak tertinggalnya informasi yang baru dalam pemberian makanan tambahan yang baru boleh diberikan pada bayi usia 6 bulan keatas, atau sebaliknya bila pendidikan rendah kemungkinan akan menghambat seseorang untuk menerima informasi baru sehingga masih banyak ibu yang memberikan makanan tambahan pada bayi usia kurang dari 6 bulan.

\section{KESIMPULAN}

Berdasarkan analisis dan pembahasan hasil penelitian yang telah disebutkan maka dapat disimpulkan :

1. Distribusi frekuensi responden yang memiliki pengetahuan kurang baik sebesar 55,8\% dan responden dengan pengetahuan baik sebesar $44,2 \%$.

2. Distribusi frekuensi responden dengan pendidikan yang rendah sebesar $27,9 \%$ dan 
responden dengan pendidikan tinggi sebesar $72,1 \%$.

3. Distribusi frekuensi responden yang memberikan MP-ASI pada bayi usia <6 bulan sebesar 23,3\% dan responden yang tidak memberikan MP-ASI sebesar 76,7\%.

4. Ada hubungan bermakna antara pengetahuan dengan pemberian MP-ASI pada bayi usia $<6$ bulan dengan nilai signifikan $(0,001)$.

5. Ada hubungan bermakna antara pendidikan dengan pemberian MP-ASI pada bayi usia $<6$ bulan dengan nilai signifikan $(0,017)$.

\section{SARAN}

Saran yang ingin disampaikan peneliti untuk dijadikan sebagai bahan pertimbangan yang antara lain ditunjukkan kepada RB Citra Palembang diharapkan kader atau petugas kesehatan agar melakukan penyuluhan tentang pemberian MP-ASI dan mengungkap semua kesalahan dari setiap masalah untuk mengetahui kebenarannya dan paradigma atau pandangan ibu mengenai pemberian MP-ASI. Untuk kelengkapan data pada STIK Siti Khadijah dapat melengkapi referensi buku-buku mengenai konsep khususnya mengenai MP-ASI guna menunjang penelitian mahasiawa dalam menyelesaikan penelitian. Selanjutnya untuk peneliti bahwahasil penelitian merupakan informasi baru dan dapat digunakan sebagai bahan referensi untuk melakukan penelitian serta sumber penelitian yang akan datang agar penelitian berikutnya bisa dilakukan dengan variabel- variabel yang berbeda, dengan metode yang berbeda dan sampel yang lebih banyak.

\section{DAFTAR PUSTAKA}

1. Andriani, Fiska.2014.Hubungan Sosial Ekonomi dengan Kelengkapan Imunisasi TT pada Ibu hamil di RS AK Gani Palembang Tahun 2014.Palembang:STIK Siti Khadijah.

2. Citerawati, Yetti Wira.2016. Makanan Pendamping ASI.Yogyakarta:Transmedika.

3. Dinkes Sumsel.2015.Profil Kesehatan Sumatera

Selatan.(www.dinkes.sumselprov.go.id) diakses tanggal 29 Mei 2017)

4. Dinkes Kota Palembang. 2015.Profil Kesehatan Kota

Palembang (www.dinkes.palembang.go.id) diakses tanggal 29 Mei 2017)

5. Fikawati, dkk.2015. Gizi Ibu dan Bayi.Jakarta:Rajawali Pers.

6. Ginting, dkk.2013.Pengaruh Karakteristik, Faktor Internal dan Eksternal Ibu Terhadap Pemberian MP-ASI Dini pada Bayi Usia <6 Bulan di Wilayah Kerja Puskesmas Barusjahe Kabupaten Karo Provinsi Sumatera Utara. Bandung:Universitas Padjajaran.

7. Kusmiyati, dkk.2014.Hubungan Pengetahuan, Pendidikan dan Pekerjaan Ibu 
dengan Pemberian Makanan Pendamping ASI (MP-ASI) pada Bayi di Puskesmas Bahu Kecamatan Malalayang Kota Manado.Manado:Poltekes Kemenkes Manado.

8. Kemenkes RI.2015.Profil Kesehatan Indonesia.(www.depkes.go.id) diakses tanggal 29 Mei 2017)

9. Kemenkes RI.2015.Pedoman Gizi Seimbang.Jakarta:Kementrian Kesehatan RI.

10. Mardalena, I.2017.Dasar-dasar Ilmu Gizi: Konsep dan Penerapan Pada Asuhan Keperawatan.Yogyakarta:Pustaka Baru Press.

11. Maryani, dkk.2015.Faktor-faktor yang Berhubungan dengan Pemberian MP-ASI Dini di Wilayah Kerja UPTD Puskesmas Sindanglaut Kecamatan Lemahabang Kabupaten Cirebon.Cirebon:Poltekes Tasikmalaya.

12. Muthmainnah 2010.Faktor-faktor yang Berhubungan dengan Pengetahuan Ibu dalam Memberikan Makanan Pendamping ASI di Puskesmas Pemulang 2010.Jakarta:UIN Syarif Hidayatullah.

13. Notoatmodjo, S.2012.Metode Penelitian Kesehatan.Jakarta: Renika Medika.

14. Profil RB Citra Palembang, 2017

15. SDKI,2012.Infodatin ASI.(www.depkes.go.id) diakses tanggal 29 Mei 2017.
16. Saifuddin. 2010 . Buku Ajar Asuhan Kebidanan Nifas Normal. Jakarta : Kawan Pustaka.

17. Saputri.2013.Alasan Ibu Memberikan Makanan Pendamping ASI (MP-ASI) Dini dengan Pendekatan Teori Health Belief Model di Wilayah Kerja Puskesmas Kecamatan Pesanggrahan Jakarta Selatan.Jakarta:UIN Syarif Hidayatullah.

18. Setyaningsih. 2010. Prosedur Makanan Tepat untuk Balita. Jakarta : Kawan Pustaka 19. STIK Siti Khadijah.2017.Pedoman Penulisan Karya Tulis Ilmiah Program Studi Diploma III Kebidanan.Palembang:STIK Siti Khadijah.

20. Tungka,Y.2014.Faktor-faktor yang Berhubungan dengan Pemberian MP-ASI pada Bayi di Wilayah Kerja Puskesmas Gintu Kecamatan Lore Selatan Kabupaten Poso Tahun 2014.Makasar:STIKES Makasar. 